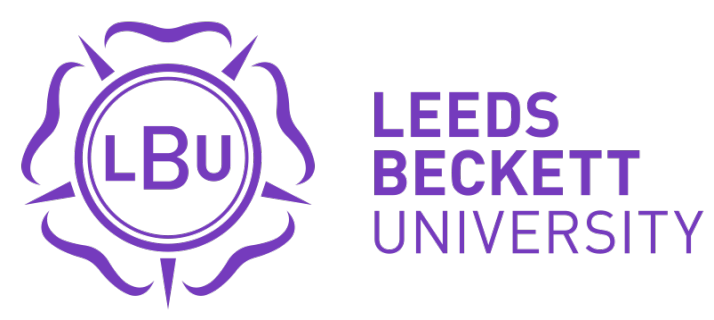

Citation:

Ramirez-Gutierez, AG and Cardoso-Castro, PP and Tejeida - Padilla, R (2020) A methodological proposal for the complementarity of the SSM and the VSM for the analysis of viability in organizations. Systemic Practice and Action Research. ISSN 1094-429X DOI: https://doi.org/10.1007/s11213-02009536-7

Link to Leeds Beckett Repository record:

https://eprints.leedsbeckett.ac.uk/id/eprint/6797/

Document Version:

Article (Accepted Version)

This is a post-peer-review, pre-copyedit version of an article published in Systemic Practice and Action Research. The final authenticated version is available online at: http://dx.doi.org/10.1007/s11213-020-09536-7.

The aim of the Leeds Beckett Repository is to provide open access to our research, as required by funder policies and permitted by publishers and copyright law.

The Leeds Beckett repository holds a wide range of publications, each of which has been checked for copyright and the relevant embargo period has been applied by the Research Services team.

We operate on a standard take-down policy. If you are the author or publisher of an output and you would like it removed from the repository, please contact us and we will investigate on a case-by-case basis.

Each thesis in the repository has been cleared where necessary by the author for third party copyright. If you would like a thesis to be removed from the repository or believe there is an issue with copyright, please contact us on openaccess@leedsbeckett.ac.uk and we will investigate on a case-by-case basis. 


\title{
A methodological proposal for the complementarity of the SSM and the VSM for the analysis of viability in organizations
}

\author{
Ana Gabriela Ramirez-Gutiérrez, ${ }^{1}$ Pedro Pablo Cardoso-Castro, ${ }^{2}$ Ricardo Tejeida-Padilla ${ }^{3}$
}

This paper presents a protocol that establishes the complementarity between Soft Systems Methodology (SSM) and the Viable System Model (VSM) for the analysis of viability in organizations.

Various studies demonstrate the advantages of both hard and soft multimethodologies, especially in the field of operational research (OR). Relying on a literature review of multimethodology, the present research specifically focuses on papers that examine the resolution of problem situations in organizations using SSM and VSM. It subsequently addresses approaches to both methodologies and, as a result, presents the characteristics that favor complementarity. Thus, this research primarily contributes with a methodological proposal that integrates both SSM and VSM.

In terms of its technical-methodological approach, this study proposes a comprehensive protocol for the integration of SSM and VSM. While some studies do extol the benefits of combining the two methodologies, a systematic protocol for their integration is still lacking. As such, the protocol presented herein consists of six steps used to diagnose or design a viable organization that includes a questionnaire for detecting organizational pathologies.

Keywords: Systems thinking, Soft System Methodology, Viable System Model, complementarity, organizations

\footnotetext{
${ }^{1}$ Corresponding author. Email: agramirez@up.edu.mx Tel. +52 (33) 13682200 / Ext.4918

Universidad Panamericana. ESDAI. Álvaro del Portillo 49, Zapopan, Jalisco, 45010, México.

2 Business School, Leeds Beckett University, Leeds, UK

${ }^{3}$ Instituto Politécnico Nacional, Ciudad de México, México
} 


\section{INTRODUCTION}

As Mingers \& Brocklesby (1997) noted a couple of decades ago, the techniques, methods, and methodologies in the field of management science have grown considerably. Coming from diverse approaches, they focus on the different problems and characteristics of the object of study.

One of these approaches corresponds to the systems approach, which arose as a response to the mechanistic, unidirectional causal method found in classical science (Bertalanffy, 2006). It is a meta-discipline that seeks to solve systemic problems; that is, it focuses on the interrelationships among a large number of variables, providing a methodological approach that helps organize thoughts in an orderly and efficient manner when faced with new and far more complex problems that include totality (François, 2004). Said approach aims to build models with sufficient (ability to deal with complexity). The era of systems, as opposed to the machine age, is characterized by complexity, turbulence, and a diversity of points of view on how to deal with problems (Pérez Ríos, 2008).

Assuming the basic propositions of classical science, the systems approach assumes that the world contains structured totalities that can maintain their identities under a certain range of conditions and that they present certain general principles of "totality" (Checkland, 2001). Systems science, according to Warfield (2006), addresses the science of description, the science of design, the science of complexity and the science of action or praxeology, and, according to the basic components for science, includes 1) human beings, who create science, 2) thought, which gives it form, and 3) language, which expresses it.

It is important to note that the systems approach also includes a wide range of methodologies for solving management problems. Various authors, such as Jackson (2003, 2019), Mingers \& Brocklesby (1997), Davies et al. (2005) have categorized these methodologies based mainly on theoretical and philosophical grounds.

Soft Systems Methodology (SSM) and the Viable System Model (VSM) are among the systemic methodologies that have been most tested for the resolution of problems in organizations of various dimensions and sectors. However, most papers explore these methodologies separately, without taking into account the benefits of using them together.

This paper thus aims to present a protocol to integrate these methodologies and explore the benefits obtained from combining them. It is structured as follows: Section 2 explores the foundations of SSM and VSM separately, as well as the strengths and weaknesses of each methodology. Section 3 presents a literature review, describing the use of multimethodologies in systems, and those that use SSM and VSM together. Section 4 points to the Viplan method and Espinosa and Walker's methodology as the most successful attempts to combine SSM and VSM to date. Section 5 presents a protocol for integrating SSM and VSM. Finally, section 6 discusses the results and presents the conclusions therefrom.

\section{EXPLORING SSM AND VSM}

Soft systems include phenomena with a strong social, political or human component. In this kind of system, the object and method of study are unknown. According to Checkland (2001), complexity and confusion exist in soft systems; however, the observer can explore it as a learning system. One of the most well-known and used methodologies for the study of soft systems is Checkland's Soft Systems Methodology (SSM).

\section{SSM}

The SSM is a methodology of social reality developed by Checkland (2001), based on Husserl's (1983) phenomenology, it takes cues from hermeneutics, including the importance of context (Schleiermacher, 1974). Therefore, as a methodology, it focuses on the study of problems, or phenomena of problems, with a strong social, political, or human component. The researcher becomes a participant in the action and the change process becomes the object of study.

The associated methodology consists of seven stages that are described in logical sequence, but are not necessarily employed in such sequence. Its utility is not restricted to the use of each and every one of its steps, but rather it adapts said steps and their sequence to the situation to be resolved (Checkland, 2001). The methodology contains two types 
of activities - "real world" activities, which necessarily include the human factor in a problem situation, and "systems thinking" ones, which require the use of higher order language or metalanguage.

According to Checkland, the first two stages bring the problem situation at hand to light, aiming to reveal a range of possible and relevant options. These stages are carried out in the real world and involve perception. Stages 3 and 4 incorporate the formal use of systems ideas and involve prediction, whereas stage 5 involves comparing the model with what exists in the real world. Finally, stage 6 involves deciding what to do as a result of previous comparison, and stage 7 brings implementation. This process is iterative and step 7 is often step 1 for another problem situation.

Checkland (2001) mentioned although the methodology with its seven stages has turned out to be resilient and functional in studies carried out in different disciplines, it shows a transformation of said model to facilitate its application. This model is shown in Figure 1, highlighting in red the actions corresponding to the seven-step model.

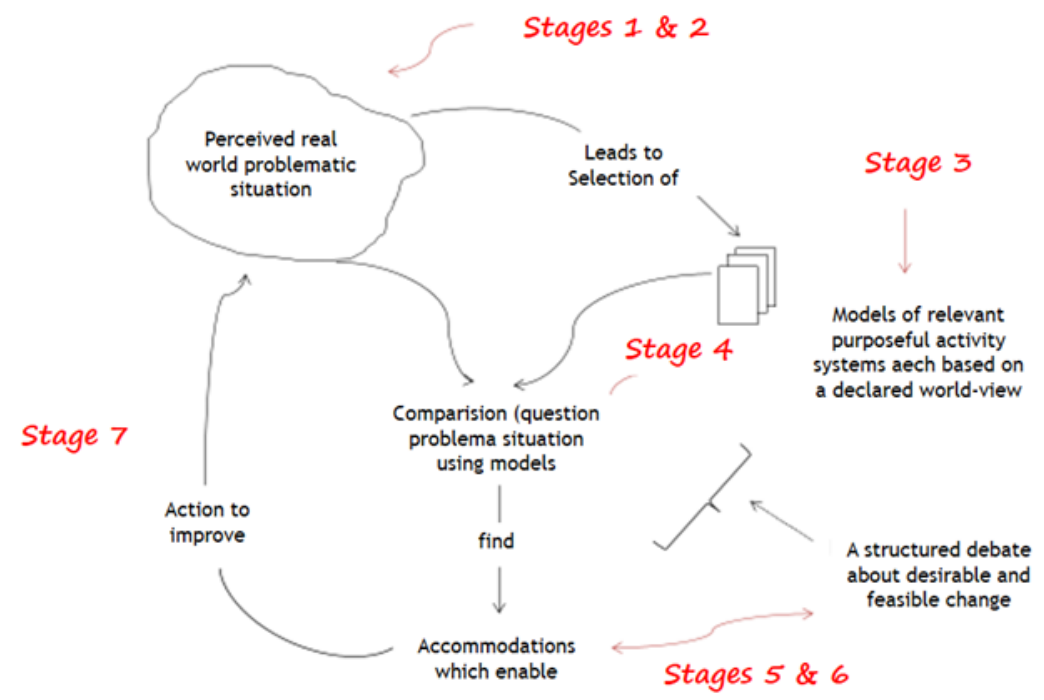

Figure 1. Soft System Methodology

Source: Modified from Checkland (2001)

Mingers (2000) refers to several limitations associated with SSM, including i) the lack of any kind of structural social theory capable of going beyond the world of individual meanings, ii) the failure to recognize the importance of power and politics, iii) problems associated with inducing change in organizations, that is, the implementation of recommendations, and iv) the lack of guidance on facilitation in the face of analysis and other problems, especially within information systems. Some of these challenges have been addressed during more than 20 years of application of the methodology, however these limitations can be understood as a result of the conception of the SSM as a methodology to solve questions akin to "what is sought to be solved?" instead of "how to solve it?" for which some other methodologies are more appropriate. Perhaps that is why most of the reported studies that use SSM do not reach the implementation phase of the desirable and feasible changes, namely, the last stage of the methodology (see e.g. Hanafizadeh \& Mehrabioun, 2018)

To fill the gap that SSM presents and to strengthen answers to questions of "how" and "with what," other methodologies can be used to complement it (Tejeida Padilla, Cruz Coria, \& Briones Juárez, 2016).

\section{VSM}

The Viable System Model (VSM) is a methodological tool that has been used around the world (Espejo, Bowling, \& Hoverstadt, 1999; Espinosa, 2015). It was developed by Beer (1994) as a theory of organizational viability based on cybernetics and neurophysiology, and it proposes a neurocybernetic model of organizations conceived as viable systems. Beer suggests that the human nervous system sets the rules for survival through processes of regulation, learning, adaptation, and evolution. He introduced the organizational cybernetics concept as a result of exploring the application of cybernetics within organizations, using Ashby's black box concept (Cardoso Castro, 2011). A black box 
is defined as a box in which inputs are observed and from which the results that emerge are also observable (Beer, 1994).

According to Beer (1990), VSM tries to provide the necessary and sufficient conditions associated with viability for any system that recognizes its own identity and, in so doing, invites others to recognize it as such. A system is thus understood as any subjective phenomenon that is recognized and, consequently, modified by its observers, which includes itself. It is, in turn, embedded in an environment with which it constantly interacts.

VSM has three basic guiding elements for the operation of said system (Figure 2). Including i) the environment in which the system operates, which can be defined as the market it serves, ii) the operation system, which is responsible for the development of goods and/or services that the organization offers, and iii) the management unit, which is responsible for ensuring the system's operation proper functioning (Beer, 1985).

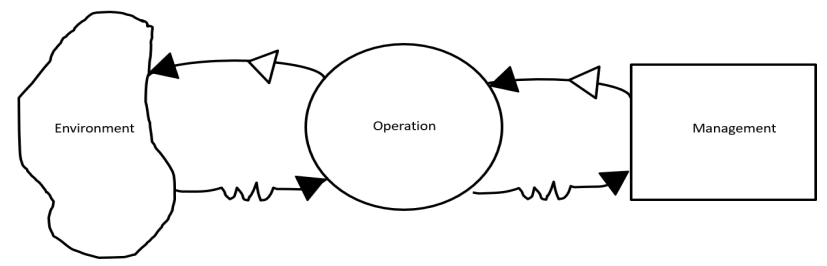

Figure 2. Basic elements for viability Source: Based on Beer (1985)

These elements are essential for ensuring a system's viability and are understood as systems nested in one another, that is, as the same organizational form at different recursive levels or as a viable system that contains and is contained in other viable systems.

In addition, this system has two elements, namely attenuators and amplifiers, which help regulate variety. The former absorb only what the system requires from among the environment's vast variety. The latter amplify the variety that the system aims to give to the environment.

Figure 3 illustrates VSM. It contains five subsystems, which continuously interact in order to maintain homeostatic equilibrium or control within the system. The regulatory process seeks to ensure the system's short and long-term survival through learning, adaptation, and evolutionary processes.

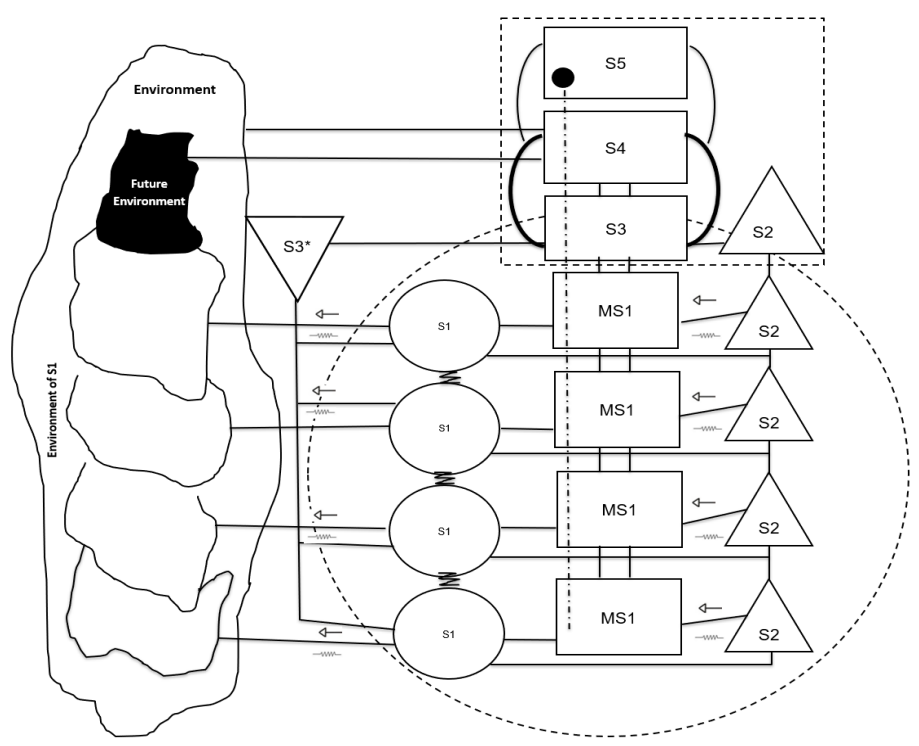

Figure 3. VSM

Source: Based on Beer (1985) 
Beer (1985) identified the five subsystems as follows:

System 1 is responsible for producing and delivering the goods and services that the organization generates to the environment. It can be defined as operation units.

System 2 is in charge of ensuring harmonious operation among the operation units that constitute System 1.

System 3 manages System 1. This system deals with the organization's "here and now."

System 4 mainly takes care of the organization's future and environment.

System 5 constitutes the highest authority in the organization. It balances the organization's present and future, taking into account the internal and external factors that affect it.

System $3 *$ is also integrated, serving as a support system that captures or audits information on system 1's operation.

VSM can be used at the theoretical or methodological level, or it can be applied. It is important to highlight that, according to Beer (1994), VSM is not well understood given that it is often described as a hierarchical, deterministic and prescriptive model.

Unlike SSM, VSM is a methodological tool that helps answering the "what" and "how" in a problem situation; however, it only addresses problem situations associated with organizational structure, and does not aid in identifying the root definition of the relevant systems.

Thus, given that these methodologies are helpful for complex systems and can therefore be applied to soft and phenomenological systems, they are both used in the present research. Together SSM and VSM are able to offer a complete diagnosis of a problem situation, as well as present a solution to it, in an iterative process. The use of both methodologies in conjunction has been shown to convert the subjectivity in conceptual models to operational models since it not only increases conceptual models' operational capacity, but also increases activity models' control capacity with a purpose defined using a cybernetic approach (Hanafizadeh \& Mehrabioun, 2018).

\section{LITERATURE REVIEW}

According to Mingers and Brocklesby (1997), multimethodology is the art of using more than one methodology or parts of methodologies together in order to consider diverse problems. It is important to enrich this conceptualization by adding related theoretical and practical approaches to instances of complexity-laden problem solving.

Mingers (2000) identifies three main arguments in support of multimethodology, including the fact that i) real world problem situations are multi-dimensional with physical or material aspects, social and political aspects, as well as personal ones, ii) an intervention is not usually a discrete event, but rather proceeds through a number of phases that present a variety of tasks and problems for practitioners, and iii) combining different methods can triangulate situations, which, in turn, generates new insights and provides the possibility of validating results. While most methods require a specific focus to deal with the problem at hand, multimethodology takes into account the complexity of a real-world problem. Combining methods and making use of quantitative and qualitative models is thus necessary for tackling the varied nature of problems.

As the number of modeling methods (hard and soft) has grown, so too has the opportunity to combine more than one method. Some authors (Bowers, 2011; Castellini, 2018; Davies et al., 2005; Estellita Lins, Netto, \& de Castro Lobo, 2019; Fong \& Chan, 2015; Pollack, 2009; Small \& Wainwright, 2014; Taket \& White, 1998) have approached the study of multimethodology based on the work of Mingers \& Brocklesby (1997). This specific approach engenders a discussion of which methods should be used and when, and if it is possible to combine hard and soft methods. Theoretically, this often relates to the problem of jumping between "hard" or deterministic and "soft" or interpretivist paradigms. Many academics see them as ontologically and epistemologically distinct, and even in direct philosophical contradiction. Practitioners are not as concerned with theory, and instead perceive and experience these problems far more pragmatically (John Mingers \& Brocklesby, 1997). 
Systems science as a discipline has both breadth and depth, that is, it has a full span of knowledge of a subject and a capacity to extent to specific topics. However, specifically within the two methods studied here, systems modeling can be used to increase understanding of complex systems through the exploration of cause-effect and decision making, often in light of feedback. Attempts to complement methodologies exist in systems science; they aim to solve problem situations by taking into account their complexity.

One tool that is very helpful for locating systemic methodologies corresponds to the problem context grid. Jackson (2019) offered a revised version of his System Of Systems Methodologies (SOSM) (2003). According to the author (2019), the SOSM was designed to classify existing systems methodologies and to probe the relationships between them. The SOSM continued to receive support from other systems thinkers looking to classify systems approaches according to their underlying assumptions and what they are most useful for. As a result, three modifications to the original grid are worth mentioning, including i) the distinction between "complicated" and "complex" contexts, which the Cynefin framework made (Kurtz \& Snowden, 2003), bringing additional resolution to the vertical dimension, ii) the "participants" dimension became "stakeholders" to include not only those affected but also those involved. According to Jackson that concept is also more widely used and better understood, and iii) the "systems" dimension was reversed to present the most aesthetically pleasing panorama of complexity that increases diagonally from bottom left to top right. Figure 4 presents Jackson's revised SOSM (2019).

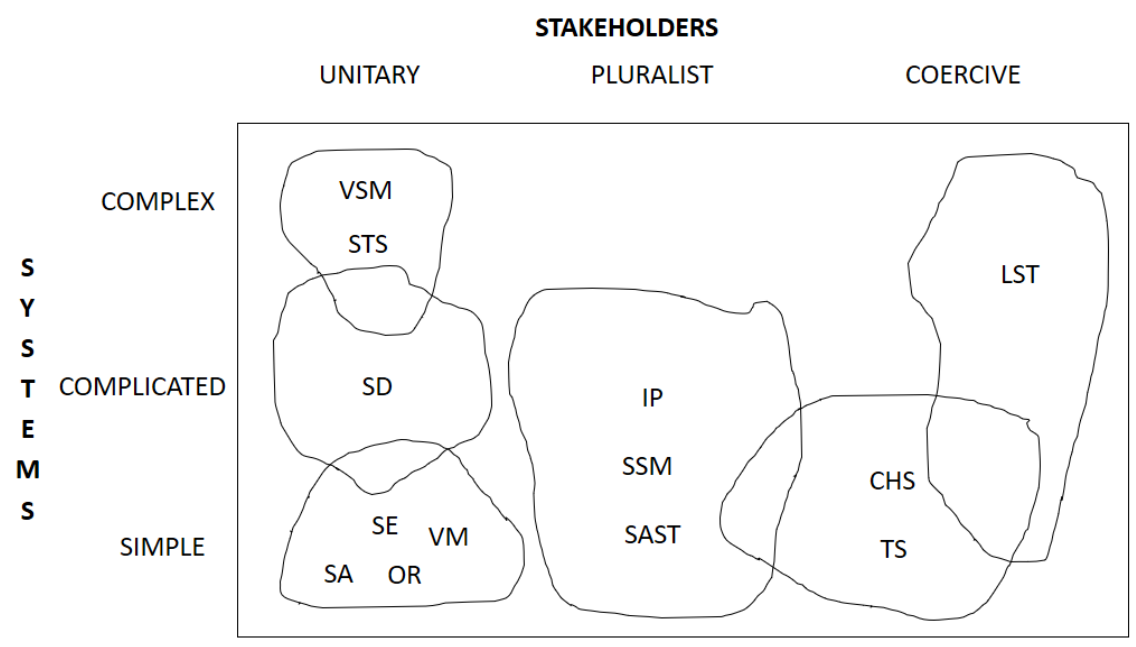

Figure 4. The positioning of liberating systems theory on the SOSM Source: Based on Jackson (2019)

According to Figure 4, VSM is classified as a methodology to address unitary-complex problems, while SSM addresses simple-pluralistic problems. However, as Jackson has pointed out, this classification is unable to say anything about particular "real-world" problem contexts or about how frequently they occur.

\section{Integration of SSM and VSM}

For Mingers (2000), SSM, like VSM, is a highly efficient methodology for organizational intervention. Some authors have used SSM and VSM together (Bustard, Sterritt, Taleb-Bendiab, \& Laws, 2006; Ganzert, Martinelli, \& Delai, 2012; Hildbrand \& Bodhanya, 2017; Kinloch, Francis, Francis, \& Taylor, 2009; Liboni, Cezarino, Caldana, \& Donaires, 2015; Luckett, Ngubane, \& Memela, 2001) to try to respond to problems in various sectors; however, these attempts are few and far between. Mingers (2000) and Hanafizadeh \& Mehrabioun (2018) report 11 papers that use SSM and VSM together; nonetheless, according to our literature review, only 9 of them really integrate both methodologies. This is because several of them only extol the importance and benefit of using both methodologies together. However, at the time of generating the case study, most only use the SSM.

Table 1 organizes the studies that integrate SSM and VSM and includes a description of their instructions for integrating both methodologies: 
Table 1. Literature review on the integration of SSM and VSM

\begin{tabular}{|c|c|}
\hline Reference & Integration of SSM \& VSM \\
\hline (Luckett et al., 2001) & $\begin{array}{l}\text { VSM is used as part of stage } 4 \text { in SSM to build conceptual models. VSM is not } \\
\text { unfolded. }\end{array}$ \\
\hline (Bustard et al., 2006) & $\begin{array}{l}\text { The authors present a four-stage design process for autonomic computing } \\
\text { systems. In stage 1, an environmental design (system model) is developed using } \\
\text { SSM. This is then refined using VSM to ensure that the viable requirements are } \\
\text { adequately covered. At this point, the context for the autonomic computing } \\
\text { system must be defined. SSM models can then be broken down to a lower level } \\
\text { to describe the autonomic system, coupled with other computation-oriented } \\
\text { modeling techniques such as UML (ODT: Other Design Technique) to produce } \\
\text { autonomic system design. This design can be fine-tuned by evaluating it in } \\
\text { relation to VSM in the fourth stage. Refining SSM models using VSM means } \\
\text { analyzing them to identify VSM subsystems and ensure that they are adequately } \\
\text { represented. This may result in adjustments to the study's conceptual models and } \\
\text { corresponding root definitions. }\end{array}$ \\
\hline (Ormerod, 2005) & $\begin{array}{l}\text { The author proposes a methodology that integrates different approaches as } \\
\text { central methods: Interactive Planning Approach (to envisage the future and then } \\
\text { making it a reality), SSM (the imperatives phase), systems thinking and VSM } \\
\text { (the insight phase) and the Strategic Choice Approach (SCA) (the intent and } \\
\text { imperative phases). Moreover, the central methods are enriched by the use of } \\
\text { other methods, such as De Bono's six thinking hats and Porter's analysis of the } \\
\text { five forces. }\end{array}$ \\
\hline (Kinloch et al., 2009) & $\begin{array}{l}\text { This article integrates SSM and VSM, plus Geographical Information System } \\
\text { (GIS) as a framework for planning information systems. VSM is used as part of } \\
\text { stage } 4 \text { in SSM. }\end{array}$ \\
\hline (Paucar-Caceres, 2009) & $\begin{array}{l}\text { The authors use SSM and VSM to measure the performance of a system } \\
\text { comparing, rather than integrating, the methodologies. For SSM, performance is } \\
\text { measured with the three Es: Efficacy, Efficiency and Effectiveness. In VSM, it } \\
\text { is measured by three different levels of Achievement: Actuality, Productivity and } \\
\text { Potentiality, respectively. }\end{array}$ \\
\hline (Ganzert et al., 2012) & $\begin{array}{l}\text { The authors propose the Intelligence Systems Methodology (ISM). With the } \\
\text { integration of SSM and VSM focused solely on the role of the intelligence } \\
\text { function, they elaborate a model of action with a structured methodology to } \\
\text { envision, select, treat, and distribute information to the entire organization in } \\
\text { order to improve the efficacy and efficiency of all processes. }\end{array}$ \\
\hline $\begin{array}{l}\text { (Darivandi Shoushtari, } \\
\text { 2013) }\end{array}$ & $\begin{array}{l}\text { The author proposes a methodology starting from functionalist and social } \\
\text { approaches. In terms of functionalism, he uses VSM to model the system and to } \\
\text { create a cybernetic diagnosis. He also uses it in combination with SCOR model } \\
\text { (Supply Chain Operations Model) to design a new managerial system for the } \\
\text { supply chain in conjunction with the social stream. SSM is used from social } \\
\text { stream to identify key stakeholders and their viewpoints with the CATWOE for } \\
\text { an interpretive and emancipatory analysis. }\end{array}$ \\
\hline (Liboni et al., 2015) & $\begin{array}{l}\text { The authors use VSM as part of SSM's fourth stage to construct conceptual } \\
\text { models. }\end{array}$ \\
\hline
\end{tabular}


(Hildbrand \& Bodhanya, 2017)
SSM and VSM are used, together with qualitative research methods, to explore possibilities for the improvement of two sugarcane production and supply systems.

This research highlights the importance of both methodologies for dealing with complex systems; however, they are used separately.

As seen in the above table, some authors (Kinloch et al., 2009; Liboni et al., 2015; Luckett et al., 2001) integrate VSM as a part of SSM's fourth stage to build conceptual models. However, the system in focus is not recognized and VSM is not unfolded. Other authors, like Bustard et al. (2006), Ormerod (2005), and Hildbrand \& Bodhanya (2017), use SSM and VSM in conjunction with other approaches to tackle specific system-based problem situations. Another study, carried out with a computational system by Bustard et al. (2006), proposes the integration of SSM and VSM for the generation of autonomous systems and their environment. Through the integration of methodologies, the authors intend for the autonomic system to be aware of its environment and adapt, as necessary, to any changes posed thereby. Bustard et al. present a more structured SSM in an attempt to cover the subsystems of VSM.

However, this review of previous studies reveals that none of the authors deploy VSM on its own or present clear protocol for the integration of the methodologies and the benefits that such integration entails.

To understand the benefits of integrating SSM and VSM, it is important to remember that, according to Beer (1990), VSM is not appropriately understood. In fact, VSM can be seen as a tool that helps SSM to operationalize conceptual models. It not only increases the operational capacity of the conceptual models, but also uses a cybernetic approach to increase the control capacity of the activity models with purpose (Bustard et al., 2006; Kinloch et al., 2009; PaucarCaceres, 2009).

Checkland (2001) allows for the application of methodologies according to the Weltanschauung or researcher's worldview. Thus, he indicates that each step in a methodology does not need to be strictly used and order is not essential. Furthermore, he mentions that a rich vision will be as simple or meticulous as the observer allows it to be.

Hanafizadeh and Mehrabioun (2017) conducted a literature review of research that uses SSM. With 149 articles published between 2000 and 2015, they identified its application in areas such as information systems development, general problem solving, education, project management, performance management, and sustainable development. In the same way, they studied its application for the resolution of problem situations, identifying that the majority of the authors used SSM for the generation of root definitions, followed by CATWOE analysis and the use of a rich vision. On the contrary, they did not find any proposals that included changing actions to solve a problem situation, considering the use of SSM as an inquire process. However, they find in 41 papers the change actions included when SSM is taken as an action oriented methodology. They also reviewed the use of SSM in conjunction with other complementary methodologies, finding greater use of SSM for modeling in Unified Modeling Language (UML), Group Fuzzy Cognitive Map (GFCM), VSM and Analytical Hierarchy Process (AHP).

Several authors (Espejo et al., 1999; Espinosa \& Walker, 2013; Pérez Ríos, 2008; Schwaninger, 2006) have approached VSM in their own way, each interpreting VSM as a methodology for viable organizational design. Harwood (2009) compiled authors who interpreted VSM and described their perspective. Likewise, he mentioned the importance of incorporating VSM into a methodology that reveals the organizational context. That is, it is useful for understanding the problem situation and the stakeholders involved in the system, as well as their commitment to or relationship with said system, which can be identified by employing VSM in conjunction with other methodologies, such as SSM.

\section{THE MOST SUCCESSFUL ATTEMPTS TO COMBINE VSM AND SSM: THE VIPLAN METHOD AND ESPINOSA \& WALKER'S METHODOLOGY}

With the literature review complete, this section explores Espejo's Viplan method and the methodology from Espinosa and Walker, both of which were foundational to the proposed methodology. In the work presented by Espinosa and Walker (2013), VSM is used in combination with that of Espejo et al. (1999). These methodologies were chosen 
because, in some of their stages, they incorporate stages from SSM. The two methodologies and the proposal generated from their use are explained below, presenting the combination of SSM and VSM in a clearer way.

Espejo et al.'s VSM

Espejo et al.'s proposal (1999) is called the Viplan method, which has been developed during years of VSM application in organizations of varying sizes in the public and private sectors.

According to the authors, the method has two modes. Mode I studies an existing organization, diagnosing its purpose. Mode II is a design instrument for a company that is in the process of establishing itself or in the midst of a profound identity change.

The method is applied with the following steps:

1. Establishment of organizational identity: The use of identity statements helps relevant participants to identify their interaction. A declaration of identity expresses the meaning the organization has for its members. It is considered a concise, but highly descriptive, statement of the organization as a total system, from a particular point of view. The TASCOI mnemonic (Transformation, Actors, Suppliers, Customers, Owners, and Interveners) is a useful aid for this exercise.

Espinosa and Walker (2013) also recommend TASCOI in the application of their methodology and as part of the first stage. This mnemonic is similar to the one from Checkland, CATWOE (Customers, Actors, Transformation, Weltanschauung, and Environment), for the definition of relevant systems. Comparing TASCOI and CATWOE, Espejo et al.'s (1999) inclusion of suppliers can be identified as a change.

According to the authors, TASCOI helps to identify both the transformations that the system needs to carry out in order to fulfill its self-defined purposes, as well as those that the participants involved must undergo, with an implicit link between identity statements and organizational structures. As defined in SSM, by including the elements associated with TASCOI in the organization's identity, its relevant systems are sure to be taken into consideration.

In the same way, for the establishment of an identity declaration, the authors recommend not defining a root definition, in agreement with Checkland's suggestion and that of the following formula: "Do X through Y to achieve Z" (Checkland, P.; Scholes, J., 1990).

2. Modeling structural activities: The Viplan method bases its structural models on a series of strategic considerations, such as relationships with suppliers and customers, geographical coverage, technological processes, and time. Structural modeling aims to examine the complexity of the organization as a whole, which is fundamental to its strategy and the way it works.

3. Unfolding of complexity and modeling structural levels: The Viplan method defines autonomous, emerging or constituted units as "primary activities"; moreover, a primary activity may have its own division of sub-activities and these divisions may have strategic business units and so on until the organization's products or services are delivered.

The Viplan method has mechanisms of cohesion (or monitoring control) and adaptation, which Beer (1994) calls attenuators and amplifiers.

4. Modeling distribution of discretion: For the Viplan method, this functional capacity is related to discretionary resources and related functions within each primary activity. Functional discretion can vary according to strategic considerations, that is, different aspects of functions or processes can take place at different recursive levels.

5. Modeling the organizational structure and study, diagnosis and design of regulatory mechanisms (adaptation and cohesion): The Viplan method's final step involves producing a VSM for the organization. Only at this point can an adequate discussion of the relationships between VSM functions take place. The Viplan method reassigns the systems' names, which Beer (1994) had assigned to the subsystems, as Implementation, Coordination, Cohesion, Intelligence, and Politics. 
The first step of Espejo et al.'s proposal (1999) is based on SSM, namely CATWOE and root definitions. However, one weakness in this methodology is found in that it identifies the VSM organizational design as the last step without considering which changes are actually feasible and viable, thus failing to see it as an iterative process in which the system is constantly changing.

\section{The VSM by Espinosa and Walker: Approach to SSM}

The methodology presented by Espinosa and Walker (2013) systematically demonstrates the application of VSM through a generic six-step methodology shown in Figure 5. This methodology is largely consistent with Espejo et al.'s proposal (1999) and indeed the authors include some of Espejo et al.'s tools, which, in turn, are based on SSM (Checkland, 2001). Additionally, more elements were found in this methodology throughout its various stages that may be related to SSM.

Along the same lines, Espinosa (2015) also identifies VSM as a meta-language, that is, a hermeneutical tool, for facilitating systemic interventions through structured debates on fundamental issues about self-organization and selfgovernment in communities or companies.

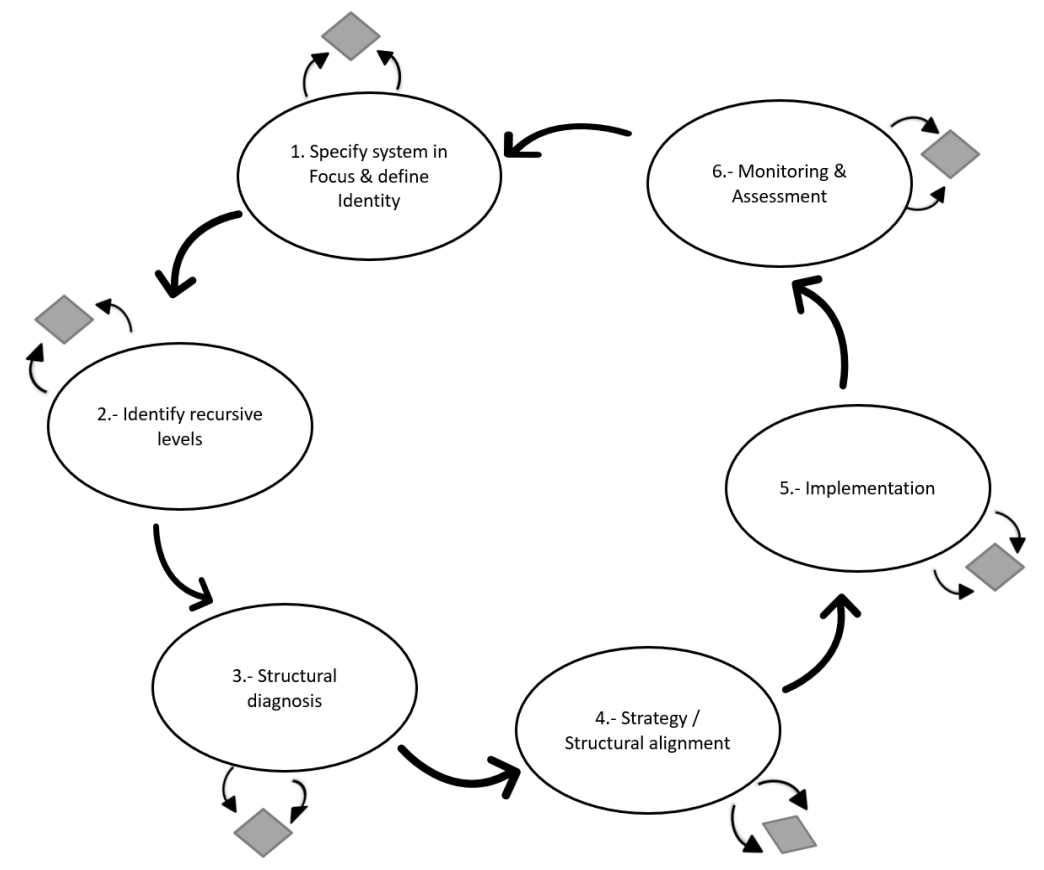

Figure 5. Methodology for the application of VSM

Source: Modified from Espinosa y Walker (2013)

This methodology proceeds as follows:

1. Specify the system under consideration and define its identity

2. Identify recursive levels

3. Carry out a structural diagnosis, identifying the weaknesses in the viability of the system, taking into account the meta questions (see Table 2). 
Table 2. Meta questions

\begin{tabular}{|l|l|}
\hline $\begin{array}{l}\text { 1. Co-evolution with } \\
\text { the environment }\end{array}$ & $\begin{array}{l}\text { Is there sufficient capacity to deal with the central problems related to viability at } \\
\text { each level of the organization? } \\
\text { What really matters to system 1; what should be measured? } \\
\text { Does system 1 work with information in real time? } \\
\text { Are there closed-loop information flows that point to effective governance? } \\
\text { Does system 1 respond quickly to changes in the environment? } \\
\text { Do environments that are effective for decision-making exist? } \\
\text { Are there adequate ways of addressing the problems of identity and closure? }\end{array}$ \\
\hline $\begin{array}{l}\text { 2. Autonomy and } \\
\text { cohesion }\end{array}$ & $\begin{array}{l}\text { Can we develop meta-systemic management to help autonomous organizations self- } \\
\text { regulate in a sustainable way? } \\
\text { Do the operational units have sufficient autonomy to perform effectively? } \\
\text { Are there mechanisms to deal with conflicting interests? } \\
\text { Are there mechanisms that synergize with system 1? } \\
\text { Are there management support systems to address critical problems that threaten the } \\
\text { organization's viability? } \\
\text { Are there ways to close the circle on critical issues that impact the organization's } \\
\text { viability? }\end{array}$ \\
\hline $\begin{array}{l}\text { 3.Recursive } \\
\text { governance }\end{array}$ & $\begin{array}{l}\text { Are problems and decisions related to local and global governance linked? } \\
\text { Are there enabling conditions for sustainable governance at each level of an } \\
\text { integrated and inclusive organization? }\end{array}$ \\
\hline
\end{tabular}

Source: Espinosa and Walker (2013)

4. Reflect on strategy vs. structure gaps

5. Implementation of the required changes

6. Monitor and review the situation

According to the authors, diagnosis in VSM requires several iterations. As seen in the diamonds in Figure 4, in order to do so, system members must collaborate and participate in the co-design process through workshops. The loop represents continuous monitoring, review, and re-thinking of the process.

Cardoso Castro \& Espinosa (2019), make use of this methodology with Social Network Analysis (SNA) to assess the process of identification of organizational pathologies.

Espinosa and Walker's proposal uses SSM at the beginning of the methodology for the construction of enriched visions, as well as for the establishment of root definitions. However, in addition to this, some phases of the methodology that could be related to some stages of the SSM are identified. Including the generation of a strategy for structural alignment according to the weaknesses found within step 4 of SSM, which consists in the generation of conceptual models; the implementation of the required changes, with stage 6 of the SSM, called desired and feasible changes, and finally the stage of monitoring and evaluation of changes, related to stage 7 of Checkland, action to improve the situation.

Although not recognized by the authors, this methodology more closely relies on SSM. Indeed, Espinosa and Walker's approach focuses on supporting self-organization in communities.

With both methodologies having been reviewed, the present investigation continues by examining the integration of both SSM and VSM. 


\section{INTEGRATION OF SSM AND VSM}

This section presents an original methodological proposal for the integration of VSM and SSM. It is the result of the aforementioned review, as well as of the authors' experience in the application of VSM and SSM (Cardoso Castro, 2019; Cardoso Castro \& Espinosa, 2019; Sánchez-García, Ramírez-Gutiérrez, Núñez-Ríos, Cardoso-Castro, \& G. Rojas, 2019; R. Tejeida-Padilla, Ramírez-Gutiérrez, \& Moreno-Escobar, 2015; Ricardo Tejeida-Padilla, Badillo-Piña, \& Morales-Matamoros, 2010).

Figure 6 clarifies the methodological approach proposed in this work, combining SSM and VSM to evaluate the organizational structure of a company or organization.

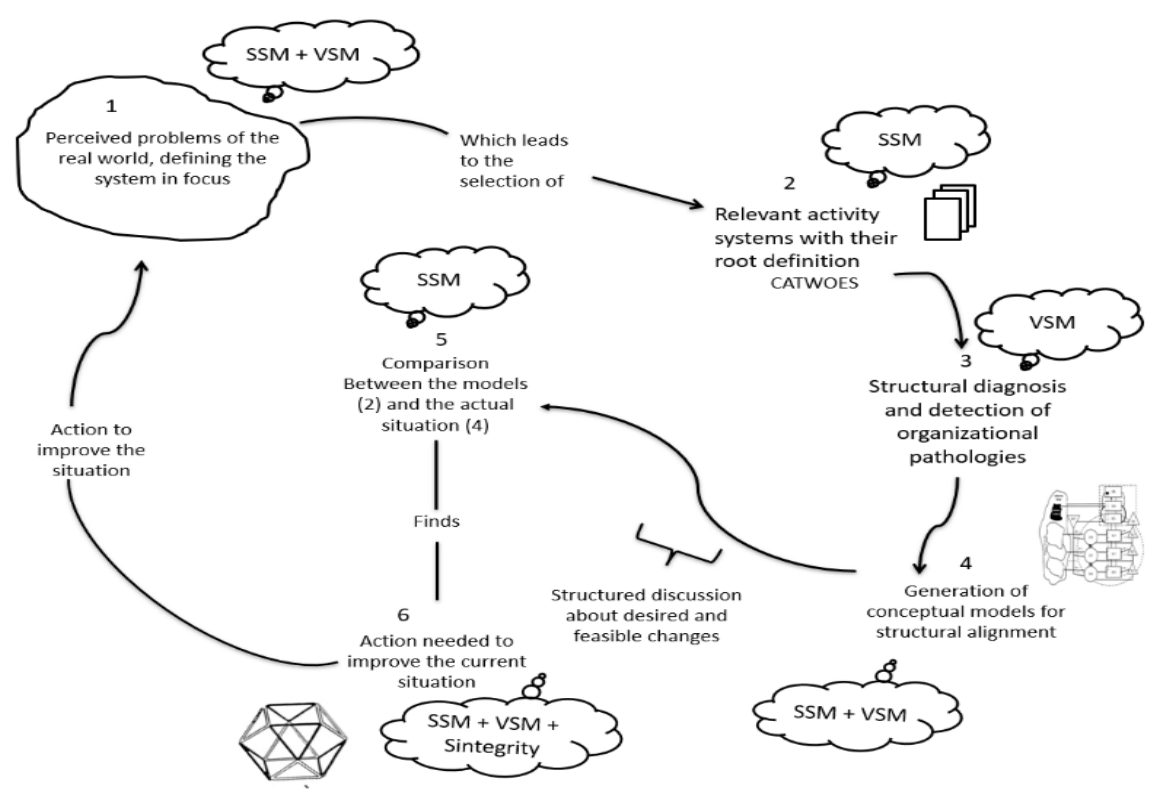

Figure 6. Methodology for combining SSM and VSM in the analysis of organizational viability

This methodological proposal integrates SSM and VSM from the start, considering both compatible and complementary proposals. The result is a six-step methodology; the steps pertain either to SSM or to VSM and, in some cases, to both. Figure 5 lays out these stages and specifies their origin. This methodology, like that of Checkland, does not distinguish real-world and systems thinking activities, taking into account that, in the real world, problematic within the organizational structure are identified from the beginning. Nevertheless, it relies on systems thinking to develop the stages, which unfold as follows:

Stage 1: Definition of perceived problems in the real world by defining the system. In this stage, once a problem situation is identified within an organization, its elements are classified, as well as those elements that are part of the environment, but that intervene in the functioning of the organization, i.e., the unstructured problem situation from SSM. In turn, enriched visions (SSM) - the first attempt to provide structure to the problem — are also developed to contextualize the unfolding complexity and to identify the recursive level and system and system in focus to be analyzed (taken from VSM). The identification of the system in focus allows the organization's internal and external elements to be located on their corresponding recursive level. The identification of these elements leads to stage 2 .

Stage 2: Selection of relevant activity systems and their root definition. In this stage, the relevant systems are identified (SSM) with the aid of the CATWOES mnemonic, which, in addition to the one described by Checkland (2001) in SSM, considers the organization's suppliers as taken from Espejo et al.'s VSM proposal (1999). Once the relevant systems have been identified, the root definition of the system in general is expressed, as well as the root definition of those relevant systems that the organization contains, due to the fact that it is a recursive and viable system. The root definition is taken from SSM. This step helps to determine, as the VSM requires, the identity of the organization. 
Stage 3: Diagnosis and detection of organizational pathologies. In this stage, a questionnaire is used to diagnose the organization's current situation (Appendix 1). Specifically, it evaluates the control functions in an organizational unit, of any size, to detect failures in all subsystems therein. This instrument helps to integrate SSM's rich vision in a structured format, evaluating the subsystems established by VSM. The questionnaire has 20 items and evaluates the control function in each of the systems proposed by VSM with a 5-point Likert scale (1 signifying "does not apply" and 5 meaning "completely applies."). The questionnaire is based on VSM's meta-questions that Espinosa and Walker (2013) proposed to accurately diagnose the organization, in conjunction with Pfiffner's questionnaire, which was tested in a case study using VSM to determine organizational crisis in banks (Pfiffner, 2017).

Subsequently, from the work of Cardoso Castro \& Espinosa (2019) the consolidated list of organizational pathologies or systemic dysfunctions is used to identify the pathologies found during the diagnosis. In this regard, the table in Appendix 2 shows the organizational pathologies for each subsystem of the VSM. According to the questionnaire, unknown scores, and those from 1 to 3, indicate an organizational pathology; otherwise, scores from 4 to 5 indicate a correctly operating system.

Stage 4: Generation of conceptual models for structural alignment. This stage presents conceptual models (SSM) that describe the organizational adjustments needed for the implementation of the organizational strategy. For the development of these conceptual models, Beer's glossary of rules for a viable system (Appendix 4) may be taken into consideration (VSM) given that the conceptual model must consider all VSM subsystems and rules.

Stage 5: Comparison between conceptual models and reality. Conceptual models are compared with the organization's current situation; such comparison aims to elucidate the existing differences between the conceptual models and the current state of the system (SSM), that is, the organizational pathologies identified (VSM). This stage aims to identify necessary implementation measures.

Stage 6: Action necessary to improve the current situation. In this stage, based on SSM and using the differences that emerged between the current situation and the conceptual models, changes that help overcome systemic pathologies are proposed. They should be desirable and viable and accord with the organization's resources. The last step involves implementation of the designed changes in order to solve the problem situation, which must be constantly monitored. Given that organizations are dynamic systems, these changes will naturally occur in an iterative process.

For the execution of this last stage, Syntegrity (Beer, 1994) for the decision-making can be considered. Full exploration of the Syntegrity technique goes beyond the limits of this contribution, however and briefly, it offers a creative, synergetic and participatory platform for group awareness in a democratic, non-hierarchical manner to capture the group's best thinking (Leonard, 1996; Pérez Ríos \& Velasco Jiménez, 2015). The number of participants in the organization can be restricted to its execution.

\section{DISCUSSION AND CONCLUSIONS}

This study presents an analysis of SSM and VSM's ability to respond to problem situations in organizations. By combining them in a protocol that uses steps from both methodologies, it relies on the elements or tools that are useful for the evaluation of an organization focused on its viability.

The literature review identified papers that contain and discuss the use of multimethodology. Mingers \& Brocklesby (1997) pointed out the importance of constructing ad hoc multimethodologies suitable for a particular problem situation. They also noted that using different methodologies leads to triangulation in information. Midgley, Nicholson, \& Brennan (2017) remarked on the importance of methodological pluralism beyond theoretical and philosophical assumptions.

In reference to studies discussing the use of SSM and VSM as a whole, only a few investigations were identified, specifically in nine research articles. Authors such as Mingers (2000) and Hanafizadeh \& Mehrabioun (2017) report the combined use of both methodologies having as a result only 11 articles. When reviewing the works that truly use SSM and VSM together, different authors present positive results using both approaches to solve organizational problems in a variety of sectors. However, these investigations do not point to clear integration of the methodologies, or to a protocol for developing their integration. Several of the studies analyzed use VSM in SSM's fourth stage, but fail to develop VSM on its own with its subsystems. 
This research takes into account the theoretical bases of both methodologies using the analytic protocols that correspond to SSM stages within VSM in such a way that questions of "what" and "how" associated with a problem situation can be answered. SSM is considered, according to its epistemological bases as a subjective methodology able to handle complexity. On the other hand, VSM is largely misunderstood as a deterministic and hierarchical methodological tool; in reality, it is also subjective and can deal with complex systems. These methodologies are aligned in their ability to deal with complexity, especially when it comes to problem situations in organizations, all of which favors their integration.

Methodologically, SSM's seven stages contain real-world activities in which the human factor and actors' active participation is crucial. On the other hand, activities associated with systems thinking involve the use of metalanguage or a more all-embracing language, that is, a language able to discuss undecidability (Beer, 1978). These characteristics are also found in VSM seen as a methodological tool, in particular in Espejo et al. (1999) and Espinosa and Walker's (2013) approaches, highlighting their complementarity.

Aspects that are common to VSM and SSM include i) a statement of the relevant systems and the root definition of the system under study, as well as the subsystems it contains. This helps to identify the stakeholders involved in the organization's operation as part of the environment and recognizes the system's identity or purpose, allowing for the analysis to focus on fulfilling it, ii) the generation of a conceptual model that allows for the establishment of the organization's ideal, taking into consideration the relevant systems, iii) discussion of the differences between the ideal and what is currently available, which leads to the integration of changes that are both systemically desirable and culturally feasible and, finally, iv) for both, dynamic organizations need iterative processes and require that implemented changes be continually monitored. In the same way, organizational dynamism regularly reveals new problem situations, starting the process all over again.

VSM and SSM's primary contributions include the following: i) SSM's primary strengths are found in identifying where a problem situation comes from and in generating a rich vision of the system; that is, in giving structure to an unstructured problem situation and in identifying the internal and external elements that are relevant to its operation. For its part, VSM identifies and seeks to solve specific problems associated with organizational structures; ii) by generating a rich vision or system-wide diagnosis, the system's pathologies can be identified; iii) the model's design comes from the structure associated with VSM, which allows for clearer identification of the relevant systems in the different levels of recursion, as well as of their root definitions. Asserting root definitions for each of the relevant systems helps verify their alignment at each level of recursion with the overall system's root definition or its general objective.

As a result of our analysis of both approaches, we presented a methodological contribution based on the complementarity between SSM and VSM in order to solve problems associated with organizational structure in social systems, which corresponds to this research's main contribution. It contains six stages, which, in turn, integrate phases and tools from SSM and VSM according to their contributions as described above. In short, this methodology allows one to identify a problem situation in context, and delineates the system in focus, as well as its organizational structure. By identifying it, we are able to reveal the overall system's root definition, as well as that of its relevant systems, seeking alignment among them. Once the relevant systems have been defined, structural diagnosis and detection of organizational pathologies can be carried out in order to generate a conceptual model for structural alignment, which must be presented with a VSM. This conceptual model reveals that an organization's ideal arises from its root definition; at the same time, it shows that detection of organizational pathologies derives from diagnosis in which a rich vision provides more substantial context and helps identify deviations in the system from the ideal. Then, by comparing reality with the conceptual model, the necessary actions needed for desirable and feasible change can be identified. For this last stage, use of Beer's Syntegrity is recommended.

This methodology is advantageous in that it presents a clear protocol for the integration of both methodologies to tackle problem situations associated with viability in organizations. It takes into consideration aspects associated with both SSM and VSM to more comprehensively diagnose organizations. The associated questionnaire allows for evaluation of organizational pathologies, making the VSM language more understandable, as well as providing a structured rich vision. 
Despite the advantages presented for the application of the methodology, the authors acknowledge that challenges and limitations can also be generated. One of the challenges and which is currently being worked on, is the ease of applying the methodology in organizations, derived from the use of VSM language and the identification of organizational pathologies. On the other hand, another limitation is that its application is only for problems of an organizational nature, leaving aside the capacity of SSM to resolve wicked problems gave in its methodology to seven steps.

Like the SSM, it is not ruled out that the application of this methodology has adjustments to the suggested stages, which, as mentioned, are based on the practice of the authors with VSM and SSM and the use of the tools that are considered relevant for its development. However, this will only be known based on the continuous application of the methodology to organizations of different dimensions and from different sectors.

\section{REFERENCES}

Beer, S. (1978) Platform for Change. John Wiley, Chichester.

Beer, S. (1990). Recursion zero: Metamanagement. Systems Practice, 3(3), 315-326. https://doi.org/10.1007/BF01062735

Beer, S. (1994). The Brain of the Firm. John Wiley.

Bertalanffy, L. (2006). Teoría General de los Sistemas. México: Fondo de Cultura Económica.

Bowers, T. D. (2011). Towards a Framework for Multiparadigm Multimethodologies. 552(October), 537-552. https://doi.org/10.1002/sres

Bustard, D. W., Sterritt, R, Taleb-Bendiab, A, \& Laws, A. (2006). Autonomic system design based on the integrated use of SSM and VSM. Artif Intell Rev, 25, 313-327. https://doi.org/10.1007/s10462-007-9031-8

Cardoso Castro, P. P. (2011). Facilitating self-organization in non-hierarchical communities. A methodology for regeneration program. Hull University.

Cardoso Castro, P. P. (2019). The viable system model as a framework to guide organisational adaptive response in times of instability and change. International Journal of Organizational Analysis, 27(2), 289-307. https://doi.org/10.1108/IJOA-01-2018-1334

Cardoso Castro, P. P., \& Espinosa, A. (2019). Identification of organisational pathologies: Exploration of social network analysis to support the viable system model diagnostic. Kybernetes, 49(2), 285-312. https://doi.org/10.1108/K-10-2018-0557

Castellini, M. A. (2018). A Conceptual Framework for Integrating Methodologies in Management: Partial Results of a Systemic Intervention in a Textile SME in Argentina. (July). https://doi.org/10.1002/sres.2552

Checkland, Peter; Scholes, J. (1990). Soft System Methodology in Action. Chichester: John Wiley and Sons Ltd.

Checkland, P. (2001). Systems Thinking, Systems Practice. Chichester: Wiley.

Darivandi Shoushtari, K. (2013). Redesigning a Large Supply Chain Management System to Reduce the Government Administration: A Socio-Functional Systems Approach. Systemic Practice and Action Research, 26(2), 195-216. https://doi.org/10.1007/s11213-012-9244-x

Davies, J., Mabin, V. J., \& Balderstone, S. J. (2005). The theory of constraints: A methodology apart? - A comparison with selected OR/MS methodologies. Omega, 33(6), 506-524. https://doi.org/10.1016/j.omega.2004.07.015

Espejo, R., Bowling, D., \& Hoverstadt, P. (1999). The viable system model and the Viplan software. Kybernetes, 28(6-7), 661-678. https://doi.org/10.1108/03684929910282944

Espinosa, A. (2015). Governance for sustainability: learning from VSM practice. Kybernetes, 44(6-7), 955-969. https://doi.org/10.1108/K-02-2015-0043

Espinosa, A., \& Walker, J. (2013). Complexity management in practice: A Viable System Model intervention in an Irish eco-community. European Journal of Operational Research, 225(1), 118-129. https://doi.org/10.1016/j.ejor.2012.09.015

Estellita Lins, M. P., Netto, S. O. A., \& de Castro Lobo, M. S. (2019). Multimethodology applied to the evaluation of Healthcare in Brazilian municipalities. Health Care Management Science, 22(2), 197-214. https://doi.org/10.1007/s10729-018-9432-z

Fong, F., \& Chan, Y. E. E. (2015). A Critical Realist and Multimethodology Framework for Product Placement Research. (2010), 279-295. https://doi.org/10.1080/10496491.2015.1021502

Franḉois, C. (2004). International Encyclopedia of Systems and Cybernetics (2nd ed.). München: Die Deutsche Bibliothek.

Ganzert, C., Martinelli, D. P., \& Delai, I. (2012). Intelligence systems methodology: a systemic approach to the organizational intelligence function. Knowledge Management Research \& Practice, 10, 141-152. https://doi.org/10.1057/kmrp.2011.44 
Hanafizadeh, P., \& Mehrabioun, M. (2018). Application of SSM in tackling problematical situations from academicians' viewpoints. Systemic Practice and Action Research, Vol. 31, pp. 179-220. https://doi.org/10.1007/s11213-017-9422-y

Harwood, S. A. (2009). The changing structural dynamics of the scottish tourism industry examined using stafford beer's VSM. Systemic Practice and Action Research, 22(4), 313-343. https://doi.org/10.1007/s11213-009-91299

Hildbrand, S., \& Bodhanya, S. (2017). Exploring the complexity of sugarcane supply chains via systemic approaches. Kybernetes, 46(2), 310-329. https://doi.org/10.1108/K-05-2014-0094

Husserl, E. (1983). Ideas pertaining to a pure phenomenology and to a phenomenological philosophy. Netherlands: Martinus Nijhoff Publishers Group.

Jackson, M. C. (2003). Creative Holism for Managers. Chichester: Wiley.

Jackson, M. C. (2019). Critical System Thinking and the Management of Complexity. Chichester: John Wiley and Sons Ltd.

Kinloch, P., Francis, H., Francis, M., \& Taylor, M. (2009). Supporting crime detection and operational planning with soft systems methodology and viable systems model. Systems Research and Behavioral Science, 26(1), 3-14. https://doi.org/10.1002/sres.943

Leonard, A. (1996). Team syntegrity: A new methodology for group work. European Management Journal, 14(4), 407-413. https://doi.org/10.1016/0263-2373(96)00028-X

Liboni, L. B., Cezarino, L., Caldana, A. C. F., \& Donaires, O. S. (2015). Diagnosing Failure in an Organizational Strategic Alliance for New Product Development. Systems Research and Behavioral Science, 32(6), 721-734. https://doi.org/10.1002/sres.2269

Luckett, S., Ngubane, S., \& Memela, B. (2001). Designing a Management System for a Rural Community Development Organization Using a Systemic Action Research Process. In Journal of Systemic Practice and Action Research (Vol. 14).

Midgley, G., Nicholson, J. D., \& Brennan, R. (2017). Dealing with challenges to methodological pluralism: The paradigm problem, psychological resistance and cultural barriers. Industrial Marketing Management, 62, 150159. https://doi.org/10.1016/j.indmarman.2016.08.008

Mingers, J. (2000). The contribution of critical realism as an underpinning philosophy for ORaMS and systems. In Journal of the Operational Research Society (Vol. 51). Retrieved from www.stockton-press.co.uk/jors

Mingers, John. (2000). An Idea Ahead of Its Time: The History and Development of Soft Systems Methodology. Systemic Practice and Action Research, 13(6), 733-755. https://doi.org/10.1023/A:1026475428221

Mingers, John, \& Brocklesby, J. (1997). Multimethodology: Towards a framework for mixing methodologies. Omega, 25(5), 489-509. https://doi.org/10.1016/S0305-0483(97)00018-2

Ormerod, R. (2005). Putting soft or methods to work: The case of IS strategy development for the UK Parliament. Journal of the Operational Research Society, 56(12), 1379-1398. https://doi.org/10.1057/palgrave.jors.2601963

Paucar-Caceres, A. (2009). Measuring the Performance of a Research Strategic Plan System Using the Soft Systems Methodology's Three "Es" and the Viable System Model's Indices of Achievement. Systemic Practice and Action Research, 22(6), 445-462. https://doi.org/10.1007/s11213-009-9140-1

Pérez Ríos, J. (2008). Diseño y diagnóstico de organizaciones viables. Un enfoque sistémico. España: Universidad de Valladolid.

Pérez Ríos, J., \& Velasco Jiménez, I. (2015). The application of organizational cybernetics and ICT to collective discussion of complex issues. Kybernetes, 44(6/7), 1146-1166. https://doi.org/10.1108/K-01-2015-0009

Pfiffner, M. (2017). System Viability of Organizations and the Aetiology of Organizational Crisis. Universität Utrecht.

Pollack, J. (2009). Multimethodology in series and parallel: strategic planning using hard and soft OR. 156-167. https://doi.org/10.1057/palgrave.jors.2602538

Sánchez-García, J. Y., Ramírez-Gutiérrez, A. G., Núñez-Ríos, J. E., Cardoso-Castro, P. P., \& G. Rojas, O. (2019). Systems Thinking Approach to Sustainable Performance in RAMSAR Sites. Sustainability, 11(22), 6469. https://doi.org/10.3390/su11226469

Schleiermacher, F. (1974). Hermeneutik, Abhandlungen der Heidelberger Akademie der Wissenschaften philosophisch-historische (2nd ed.). Heidelberg: Klasse.

Schwaninger, M. (2006). Theories of viability: A comparison. Systems Research and Behavioral Science, 23(3), 337347. https://doi.org/10.1002/sres.731

Small, A., \& Wainwright, D. (2014). SSM and technology management: Developing multimethodology through practice. European Journal of Operational Research, 233(3), 660-673. https://doi.org/10.1016/j.ejor.2013.08.049 
Taket, A., \& White, L. (1998). Experience in the Practice of One Tradition of Multimethodology. Systemic Practice and Action Research, 11(2), 153-168. https://doi.org/10.1023/A:1022977301782

Tejeida-Padilla, R., Ramírez-Gutiérrez, A. G., \& Moreno-Escobar, J. (2015). Towards a systemic business model for SMEs professional congress organizers in Mexico. Proceedings of the 59th Annual Meeting of the International Society for the Systems Sciences.

Tejeida-Padilla, Ricardo, Badillo-Piña, I., \& Morales-Matamoros, O. (2010). A systems science approach to enterprise resources planning systems. Systems Research and Behavioral Science, 27(1), 87-95. https://doi.org/10.1002/sres.957

Tejeida Padilla, R., Cruz Coria, E., \& Briones Juárez, A. (2016). Sistémica y turismo (1st ed.). México: Miguel ángel Porrúa.

Warfield, J. (2006). An introduction to Systems Science. USA: World Scientific Publishing Co.

\section{APPENDIX}

APPENDIX 1. - Questionnaire to Organizational diagnosis. Modified from Pfiffner (2017)

1. - Purpose of the questionnaire

To obtain information on the control of the functions of the organization or organizational units.

The term control function encompasses everything that produces control effects. This can include complete organizational units.

2. - Topic of the questionnaire

Evaluate a specific organization or organizational unit.

3. Content of the questionnaire

Evaluation of the control functions of a certain organization which do not have to coincide with the formal logic of the hierarchy or organizational chart of the organization. In smaller organizations, it is possible for the same person or agency to perform several control functions. Otherwise, in larger organizations, it is possible for a control function to be performed by more than one person or agency.

The survey is based on six control functions that will be found repeatedly. The functions are explained in the following table and in the questions.

Control functions

\begin{tabular}{|l|l|l|}
\hline 1 & $\begin{array}{l}\text { Operation Units (OU). Operative service providers such as } \\
\text { service centres, specialized departments, plants, branches, } \\
\text { subsidiaries, project teams, profit centres, etc. with the function } \\
\text { of control and provision of goods or services. }\end{array}$ & $\begin{array}{l}\text { In this system the product or } \\
\text { service is created, and value is } \\
\text { added (S1) }\end{array}$ \\
\hline 2 & $\begin{array}{l}\text { Coordination: regulations, instructions, systems, standards, } \\
\text { coordination bodies, reservation systems, manuals, schedules, } \\
\text { coordination meetings, interface rules, quality, security, general } \\
\text { production schedules, etc. }\end{array}$ & $\begin{array}{l}\text { It eoperablishes the rules for } \\
\text { losses among OU activities (S2) }\end{array}$ \\
\hline 3 & $\begin{array}{l}\text { Operational Management (OM): management functions that } \\
\text { optimize the results and the overall performance of the } \\
\text { organization or the OP. It assigns available resources. }\end{array}$ & $\begin{array}{l}\text { It manages the organization (all } \\
\text { glities) in global terms and from a } \\
\text { and now) (S3) }\end{array}$ \\
\hline
\end{tabular}




\begin{tabular}{|l|l|l|} 
3a & $\begin{array}{l}\text { Audit: information sources of OM for independent management } \\
\text { information (that is, not influenced by interests) }\end{array}$ & $\begin{array}{l}\text { It provides neutral information, } \\
\text { and verifies conditions and states } \\
(\mathrm{S} 3 *)\end{array}$ \\
\hline 4 & $\begin{array}{l}\text { Analysis of the environment and planning for the future: } \\
\text { observation, forecasting and interpretation of the general } \\
\text { environment, reflection of the environment against self- } \\
\text { representation of the organization (model), development, } \\
\text { courses of action }\end{array}$ & $\begin{array}{l}\text { Integrates external and internal } \\
\text { points of view and suggests / } \\
\text { initiates changes. Planning units } \\
\text { (there and then) (S4) }\end{array}$ \\
\hline 5 & $\begin{array}{l}\text { Normative management and Identity: Defining the purpose, } \\
\text { directions, norms and values of the fundamental government of } \\
\text { the organization (pilot control), as well as the objective state of } \\
\text { the organization; final decision, closing. }\end{array}$ & $\begin{array}{l}\text { It establishes the identity and } \\
\text { feneral parameters, and it makes } \\
\text { (S5) }\end{array}$ \\
\hline
\end{tabular}

Important notes:

Type of questions and type of evaluations.

- The questions are formulated as idealized situations.

- The expert evaluates, on the same scale, to what extent (i.e. how completely and how well) the organization corresponds to this ideal situation.

- The scale covers the entire spectrum from defective to mediocre and good. Therefore, it is possible that evaluations in most areas end at one end or the other on the scale.

- Rating scale:

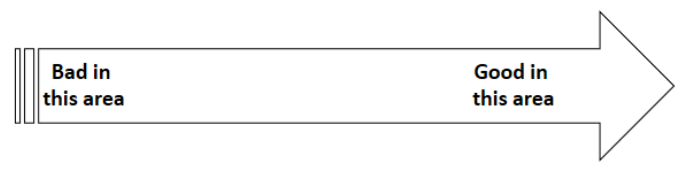

\section{Overview:}

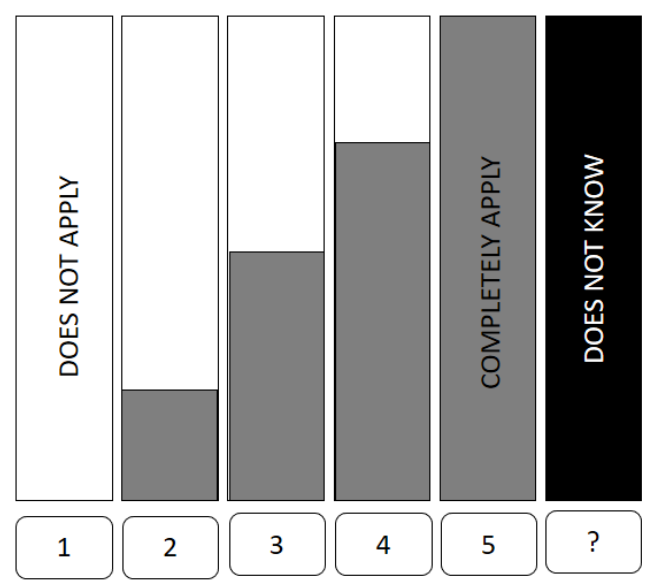

All control effects must be evaluated. Therefore, the following must be taken into account:

- Formal / official control functions, properties and structures, as well as

- Informal / unofficial control functions (that is, unofficial channels), properties and structures.

When there are significant control effects in the organization, consider it in the evaluation.

General information (Please fill in the fields) 


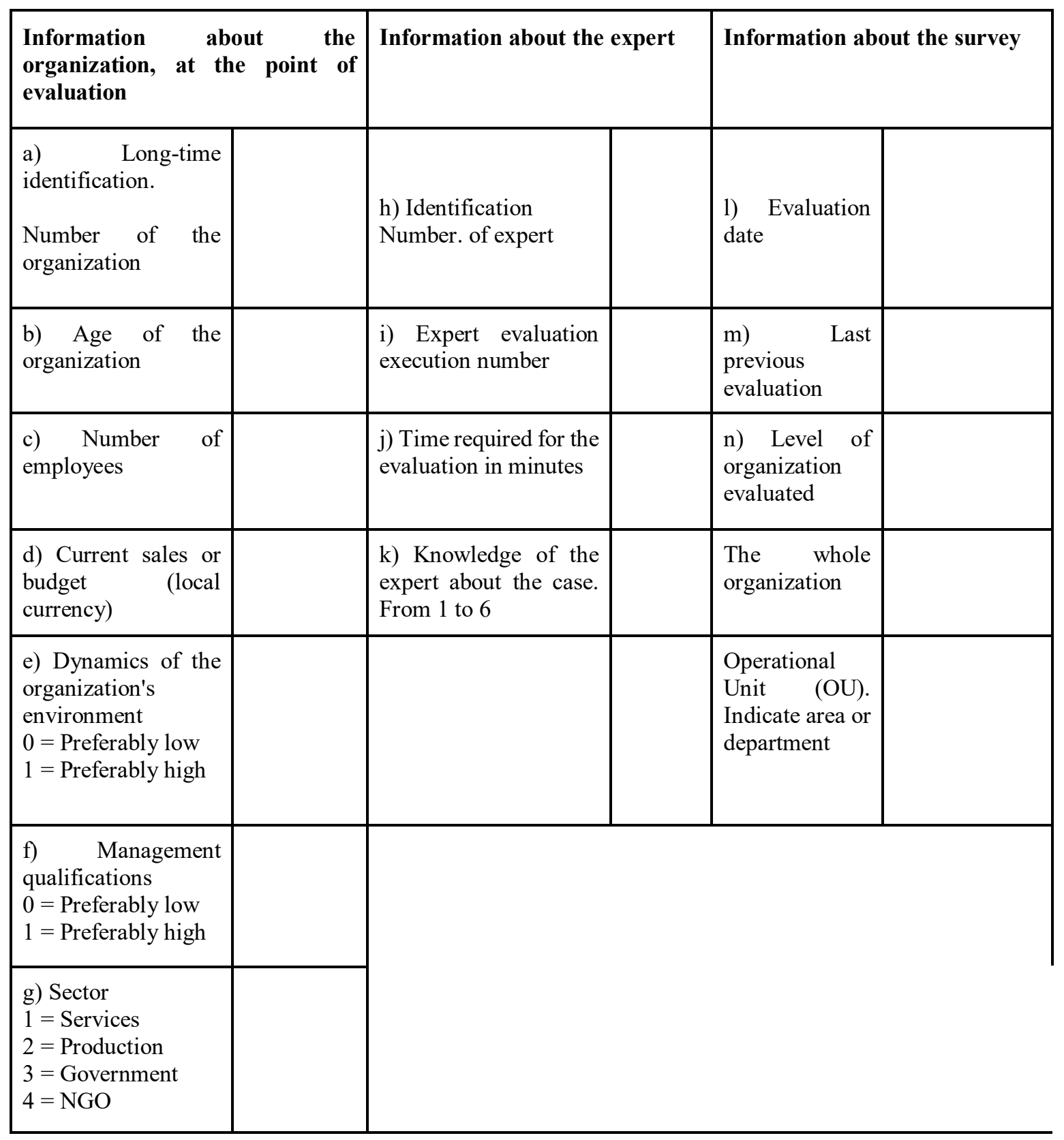




\section{Expert survey}

To what extent do you consider that the following statements are applicable to the evaluated organization?

Please use the scales to assess whether and to what degree the descriptive situation is applicable. Where you cannot do an evaluation, please make assumptions based on what you consider appropriate indicators and observations. Please use the "Do not know" column only when it is impossible for you to make an assumption. However, in most cases making an assumption will be possible.

It is possible that the evaluation in most areas ends at one of the extremes of the scale.

\section{Please check only one box $\checkmark$}

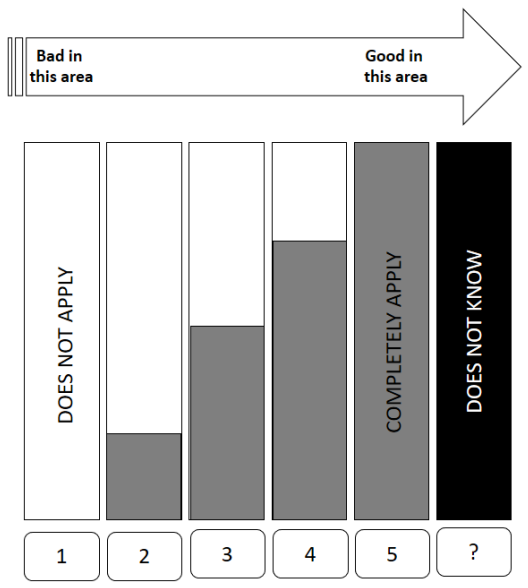

1. - Operational units for forecasting autonomous services

\begin{tabular}{|l|l|l|l|l|l|l|l|}
\hline In the organization, there is one or several Operational Units (UO) that... & 1 & 2 & 3 & 4 & 5 \\
\hline 1.1 & $\begin{array}{l}\text { f.have only responsibilities for logically definable market areas } \\
\text { (for example: by-products, customers, geographical areas, etc.). If } \\
\text { there is only one market area, the interface is defined (for example: } \\
\text { sales, marketing, project management). }\end{array}$ & $\begin{array}{l}\text {-.are competent, capable and flexible to serve their market areas } \\
\text { comprehensively (in conjunction with third parties, when } \\
\text { necessary) }\end{array}$ & & & & & \\
\hline
\end{tabular}

\section{2. - Coordination of inputs}

\begin{tabular}{|l|l|l|l|l|l|l|}
\hline $\begin{array}{l}\text { To avoid frictional losses and inefficiencies between OU, there are } \\
\text { effective coordination functions (for mutual approval, determining } \\
\text { responsibilities, limits, assignment, regulation, codes of conduct, criteria } \\
\text { for decision making, etc.), related to... }\end{array}$ & 1 & 2 & 3 & 4 & 5 & $?$ \\
\hline 2.1 & $\begin{array}{l}\text {...internal and external activities of the OU (for example: sales } \\
\text { areas, schedules, communications, methods, standards, policies, } \\
\text { information exchange, etc.). }\end{array}$ & & & & & \\
\hline 2.2 & $\begin{array}{l}\text {...resources that are used jointly by the UO, in other words, shared } \\
\text { resources (for example: reservation systems, devices, spaces, } \\
\text { funds, capacities, etc.). }\end{array}$ & & & & & \\
\hline
\end{tabular}

\section{2. - Coordination of outputs}

By constantly monitoring of the operation, the normal parameters of the organization (current and objective control parameters, the performance of tasks, quality, quantities, etc.) are... 


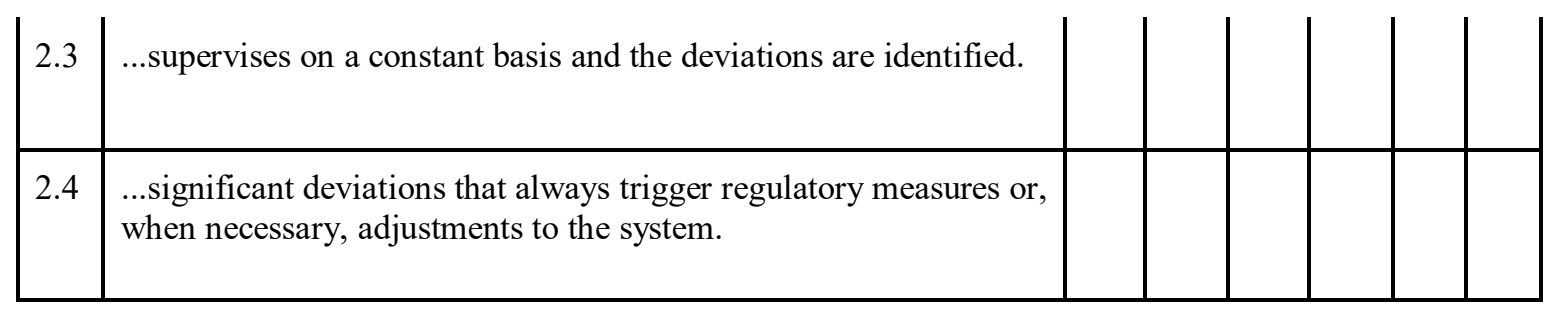

3. - Rationalization of operational management

\begin{tabular}{|c|c|c|c|c|c|c|}
\hline \multicolumn{2}{|r|}{$\begin{array}{l}\text { Operational Management }(\mathrm{OM}) \text { monitors and optimizes the functioning } \\
\text { of the organization as a whole - including itself- by means of control } \\
\text { measures, allocation of resources and changes in the parameters with } \\
\text { respect to... }\end{array}$} & 1 & 2 & 3 & 4 & 5 \\
\hline 3.1 & $\begin{array}{l}\text {...the general functioning (effectiveness, productivity, profits, } \\
\text { support services, quality or similar) in a constant or frequent and } \\
\text { systematic fashion (for example: following the rules appropriately). }\end{array}$ & & & & & \\
\hline 3.2 & $\begin{array}{l}\text {...opportunities, risks and synergies; these are always recognized, } \\
\text { used or handled appropriately. }\end{array}$ & & & & & \\
\hline
\end{tabular}

3a. - Information on operational management

\begin{tabular}{|c|c|c|c|c|c|c|}
\hline \multicolumn{2}{|c|}{ The OM gathers... } & 1 & 2 & 3 & 4 & 5 \\
\hline 3.3 & $\begin{array}{l}\text {...internal information (i.e., concerning the organization itself) and } \\
\text { external information (concerning the market and the environment) } \\
\text { for management and decision-making from an adequate } \\
\text { information system on an ongoing basis. }\end{array}$ & & & & & \\
\hline 3.4 & $\begin{array}{l}\text {...repeatedly independent information from the management line } \\
\text { regarding the state of the organization through sporadic or surprise } \\
\text { audits, surveys, direct conversations or analysis. If necessary, the } \\
\text { OM triggers regulatory measures or system adjustments. }\end{array}$ & & & & & \\
\hline
\end{tabular}

4. - Analysis of the environment and planning of future observation

\begin{tabular}{|c|c|c|c|c|c|c|}
\hline \multicolumn{2}{|r|}{$\begin{array}{l}\text { The general environment of the organization (political, environmental, } \\
\text { technological, social, legal, sectoral, market, etc.) is constantly or } \\
\text { frequently... }\end{array}$} & 1 & 2 & 3 & 4 & 5 \\
\hline 4.1 & $\begin{array}{l}\ldots \text { monitored with respect to the qualities (properties) and progress } \\
\text { that are relevant or potentially relevant to the organization. }\end{array}$ & & & & & \\
\hline 4.2 & $\begin{array}{l}\ldots \text { done with an eye on the current situation, possible scenarios and } \\
\text { future developments (future circumstances and dynamism). }\end{array}$ & & & & & \\
\hline
\end{tabular}

4. - Analysis of the environment and planning of future courses of action 


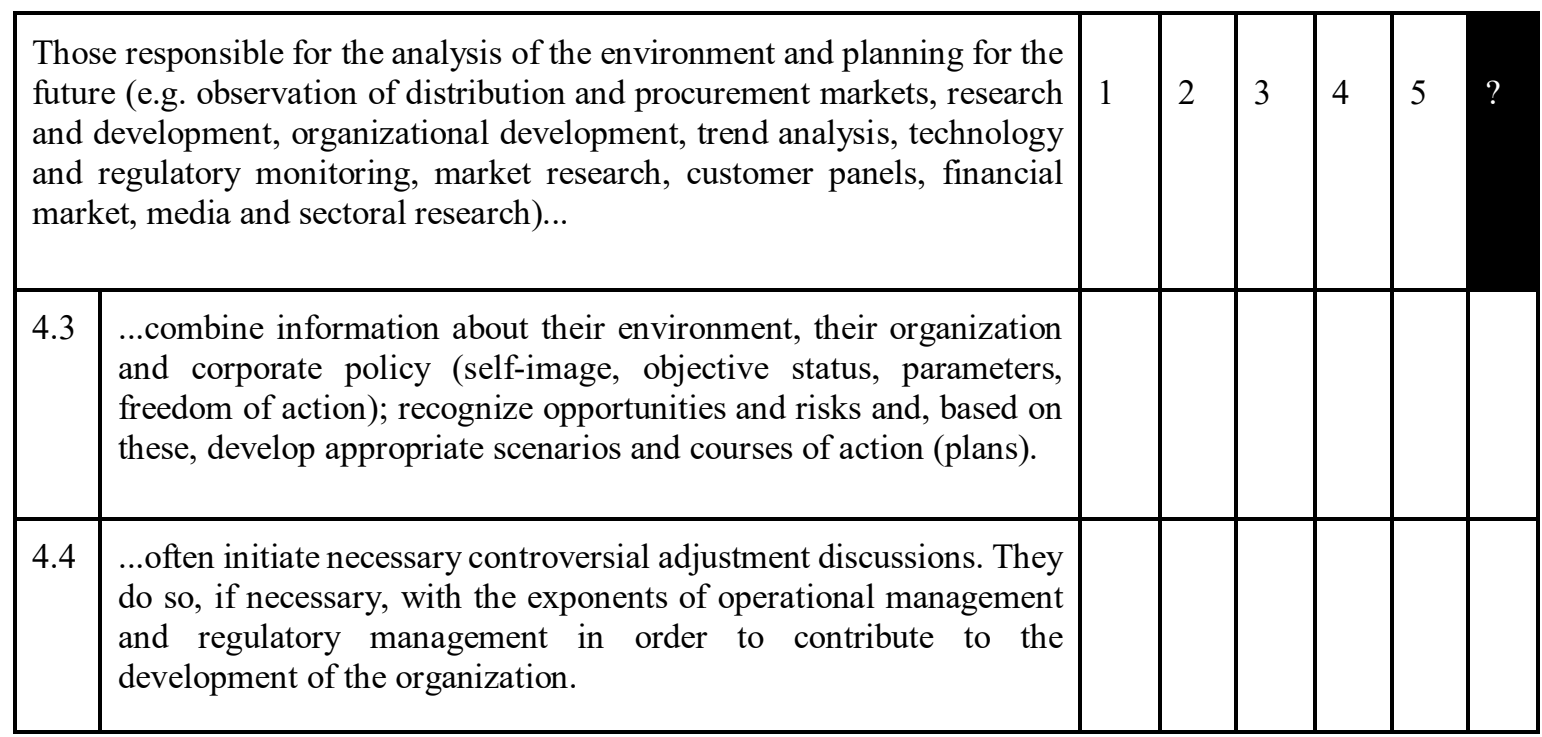

5. - Purpose, identity and normative management

\begin{tabular}{|l|l|l|l|l|l|l|l|}
\hline \multicolumn{2}{|l|}{ Regulatory management ensures ... } & 1 & 2 & 3 & 4 & 5 & $?$ \\
\hline 5.1 & $\begin{array}{l}\text {..the availability of binding guidelines and a definition of objective } \\
\text { status that informs the organization as a whole (pilot control, } \\
\text { identity) }\end{array}$ & & & & & \\
\hline 5.2 & $\begin{array}{l}\text {..that those responsible for the analysis and planning of the } \\
\text { environment for the future and operational management cooperate in } \\
\text { a way that produces the best possible development of the } \\
\text { organization. }\end{array}$ & $\begin{array}{l}\text { f. that the regulatory administration is willing and able, when } \\
\text { necessary, to make final decisions (closing the decision-making } \\
\text { process) or decisions that would fundamentally change the system } \\
\text { (basic mission change and self-concept) }\end{array}$ & \begin{tabular}{l} 
\\
\hline
\end{tabular} & & & & \\
\hline
\end{tabular}

\begin{tabular}{|l|l|l|l|l|l|l|l|}
\hline \multicolumn{2}{|l|}{ Recursive principles } & 1 & 2 & 3 & 4 & 5 \\
\hline P.1 & $\begin{array}{l}\text { The global units of the OU (e.g. company, division, branch) are } \\
\text { themselves capable of acting as independent organizations at their } \\
\text { level with all the necessary functions so that they can fulfil their } \\
\text { role independently. }\end{array}$ & & & & & \\
\hline P.2 & $\begin{array}{l}\text { The subordinate units of the OU (e.g. departments, areas, groups) } \\
\text { are able to act independently at their level with all the necessary } \\
\text { functions and can fulfil their role independently. }\end{array}$ & & & & \\
\hline
\end{tabular}

Principles of communication 


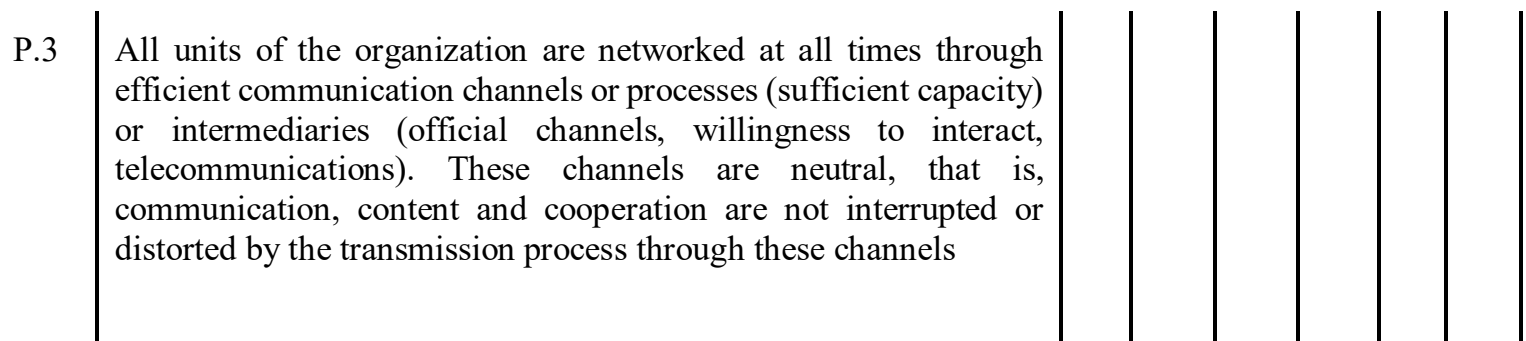

APPENDIX 2. - Organizational pathologies (Cardoso Castro \& Espinosa, 2019). In the table, the source authors reporting the pathology are reported as JPR=Jose Perez-Rios; RE\&AR=Raul Espejo and Alfonso Reyes; PH=Patrick Hoverstadt.

\section{Identity Pathologies (RE \& AR)}

\begin{tabular}{|c|c|}
\hline Pathology & Description \\
\hline 1.1 Ill-defined identity (JPR) & Organizational identity has not been created or defined \\
\hline $\begin{array}{l}1.2 \text { Lack of alignment between } \\
\text { organizational tasks and perceived } \\
\text { identity (RE\&AR) }\end{array}$ & $\begin{array}{l}\text { The organization performs tasks some of which do not correspond } \\
\text { to the espoused identity }\end{array}$ \\
\hline $\begin{array}{l}1.3 \text { Purpose in use different to the } \\
\text { espoused purpose (RE\&AR) }\end{array}$ & $\begin{array}{l}\text { Espoused purpose differs from 'purpose in use' (the one explained } \\
\text { by the tasks performed) }\end{array}$ \\
\hline $\begin{array}{l}1.4 \text { Regulatory activity acting as a } \\
\text { primary activity (RE\&AR) }\end{array}$ & $\begin{array}{l}\text { A regulatory function starts behaving as a primary function and } \\
\text { selling services to external as well as internal clients }\end{array}$ \\
\hline $\begin{array}{l}\text { 1.5 Underdeveloped primary activities } \\
\text { (RE\&AR) }\end{array}$ & $\begin{array}{l}\text { Organizational identity dominated by some primary activities at } \\
\text { the expense of a few others left behind }\end{array}$ \\
\hline $\begin{array}{l}1.6 \text { Emergent virtual organization } \\
(\mathrm{RE} \& \mathrm{AR})\end{array}$ & $\begin{array}{l}\text { The emergent virtual organization that dominates the } \\
\text { organizational identity }\end{array}$ \\
\hline 1.7 Negative synergy (RE\&AR) & $\begin{array}{l}\text { The organizational level does not add value to the operational } \\
\text { level }\end{array}$ \\
\hline $\begin{array}{l}1.8 \text { Inconsistent Primary activity } \\
(\mathrm{RE \& AR})\end{array}$ & The primary activity works for inconsistent purposes \\
\hline 1.9 Liquid Identity (RE\&AR) & $\begin{array}{l}\text { Owing to quick, constant environmental changes, the organization } \\
\text { finds difficulty to keep services or products identities for a long } \\
\text { time. The organization as networks of companies providing } \\
\text { outsourced services. S1 as 'viable core learning teams' rather than } \\
\text { 'product teams' }\end{array}$ \\
\hline 1.10 Institutional Schizophrenia: (JPR) & $\begin{array}{l}\text { Two or more identity conceptions produce conflict within the } \\
\text { organization }\end{array}$ \\
\hline \multicolumn{2}{|c|}{$\begin{array}{l}\text { II. Operational Pathologies: These are related to the way viable systems emerged and constituted recursive } \\
\text { levels of organization. Mostly with the way each system one handles complexity and its interaction with } \\
\text { upper and lower levels of organization (Authors) - coincidence with functional pathologies from JPR. }\end{array}$} \\
\hline
\end{tabular}




\begin{tabular}{|c|c|}
\hline Pathology & Description \\
\hline $\begin{array}{l}\text { 2.1 Non-existence of vertical unfolding } \\
\text { (JPR) }\end{array}$ & $\begin{array}{l}\text { Its absence drives the organization to the impossibility to deal with } \\
\text { the total variety it faces }\end{array}$ \\
\hline 2.2 Lack or recursion levels (JPR) & $\begin{array}{l}\text { Vertical unfolding is accomplished but the first level of recursion } \\
\text { is left empty leaving part of the environment unattended }\end{array}$ \\
\hline $\begin{array}{l}2.3 \text { Lack of recursion levels (middle } \\
\text { levels) (JPR) }\end{array}$ & $\begin{array}{l}\text { Vertical unfolding is accomplished but the middle recursion levels } \\
\text { are left empty. This leaves the corresponding variety to be handled } \\
\text { by the previous or next recursive level (which will cause further } \\
\text { problems) or unattended. }\end{array}$ \\
\hline 2.4 Entangled vertical unfolding (JPR) & $\begin{array}{l}\text { Various interrelated level membership. Inadequate } \\
\text { integration/communication between recursion levels when } \\
\text { multiple memberships are present }\end{array}$ \\
\hline 2.5 Weak S1 (RE\&AR) & $\begin{array}{l}\text { S1 not operating well: not recognised as a S1, poorly managed, } \\
\text { lack of self-organization, lack of autonomy and lack of } \\
\text { understanding of the local environment. }\end{array}$ \\
\hline $\begin{array}{l}2.6 \text { Dominance of S1- weak meta- } \\
\text { system (JPR) }\end{array}$ & $\begin{array}{l}\text { The power of S1 is not handled within the limits set by the meta- } \\
\text { system. }\end{array}$ \\
\hline $\begin{array}{l}2.7 \text { Disjoined behaviour within S1 } \\
\text { (JPR) } \\
\text { The Yo-Yo (PH) }\end{array}$ & $\begin{array}{l}\text { A lack of adequate interactions between the } \mathrm{S} 1 \text { lead to fragmented } \\
\text { behaviour } \\
\text { Unbalance between autonomy and cohesion. Fragmented identity. } \\
\text { Oscillating between centralized vs. devolved authority. }\end{array}$ \\
\hline 2.8 Autopoietic beast (JPR) & $\begin{array}{l}\text { Elemental operative units within the } \mathrm{S} 1 \text { behave as if their } \\
\text { individual goals were the only reason for being. They ignore the } \\
\text { need to harmonize their individual goals within an integrated S1 }\end{array}$ \\
\hline \multicolumn{2}{|c|}{$\begin{array}{l}\text { III- Meta-systemic pathologies (Authors): These pathologies relate with the way the meta-systemic roles } \\
\text { operate and interact, their constraints and resulting organizational misfits }\end{array}$} \\
\hline \multicolumn{2}{|l|}{ System 2} \\
\hline Pathology & Description \\
\hline 2.9 Weak S2 (RE\&AR) & $\begin{array}{l}\text { Misaligned purposes and values between stakeholders and } \\
\text { policymakers. Poor coordination and cohesion: different qualities } \\
\text { from products and services from S1. Lack of synergy between S1 } \\
\text { because of poor, restrictive management in the middle }\end{array}$ \\
\hline 2.10 Authoritarian S2 (Authors) & System shifts from a service provider to an authoritarian controller \\
\hline 2.11 Lack of information systems (JPR) & Some of the information systems are non-existent or inappropriate \\
\hline $\begin{array}{l}2.12 \text { Fragmentation of information } \\
\text { systems (JPR) }\end{array}$ & Information systems are in place, but they are not interconnected \\
\hline $\begin{array}{l}2.13 \text { Lack of key communication } \\
\text { channels (JPR) }\end{array}$ & $\begin{array}{l}\text { Certain communication channels that should exist are not in place, } \\
\text { they do not work, or their design is inappropriate }\end{array}$ \\
\hline
\end{tabular}




\begin{tabular}{|c|c|}
\hline $\begin{array}{l}2.14 \text { Insufficient communication } \\
\text { channels capacity. (Authors) }\end{array}$ & Insufficient communication channels capacity. \\
\hline $\begin{array}{l}2.15 \text { Lack of sufficient algedonic } \\
\text { channels (JPR) }\end{array}$ & $\begin{array}{l}\text { Necessary algedonic channels are not present or if exist, and they } \\
\text { are poorly designed and/or do not work properly }\end{array}$ \\
\hline $\begin{array}{l}2.16 \quad \text { Communication channels } \\
\text { incomplete or with inadequate capacity } \\
(\mathrm{JPR})\end{array}$ & $\begin{array}{l}\text { Necessary communication channels do not have the capacity } \\
\text { functionality for transmitting information (Transducer, channe } \\
\text { capacity and sender-receiver in both directions) }\end{array}$ \\
\hline $\begin{array}{l}2.17 \text { Weak connection between } \mathrm{S} 1 \text { and } \\
\text { S2 (Authors) }\end{array}$ & $\begin{array}{l}\text { Necessary communication with the coordination centre is not } \\
\text { present or weak }\end{array}$ \\
\hline \multicolumn{2}{|l|}{ Systems 3 and $3^{*}$} \\
\hline Pathology & Description \\
\hline 2.18 Control Dilemma (RE)(PH) & $\begin{array}{l}\text { Managers dealing with far more complexity than they should, } \\
\text { resulting in poor performance. Information overload syndrome } \\
\text { Micromanagement }\end{array}$ \\
\hline 2.19 Weak S3 (RE\&AR) & $\begin{array}{l}\text { Resource and functional centralization. Corporate intervention } \\
\text { Poor operational alignment of a centralized function with } \\
\text { operational activities. Managers bypassing lower-level } \\
\text { operational managers or vice versa }\end{array}$ \\
\hline $\begin{array}{l}2.20 \text { Inadequate management style } \\
\text { (JPR) }\end{array}$ & S3 intervenes inadequately in the affairs of S1 \\
\hline 2.21 Schizophrenic S3 (JPR) & $\begin{array}{l}\text { Conflict arises among the functions of S } 3 \text { because of its inclusion } \\
\text { in the system (operations) and the meta-system (management) }\end{array}$ \\
\hline 2.22 Hypertrophy of S3 (JPR) & $\begin{array}{l}\text { S3 concentrates much of the activity that should be carried out by } \\
\text { S3*, S2 and S1 }\end{array}$ \\
\hline $\begin{array}{l}2.23 \text { Weak S3* (RE\&AR) } \\
\text { Lack of sufficient development of S3* } \\
\text { (JPR) }\end{array}$ & $\begin{array}{l}\text { Poor or non-existent monitoring systems. Micromanagement } \\
\text { monitoring and reporting at the wrong level. } \\
\text { Lack of monitoring activity conduces to lack of action -because } \\
\text { of ignorance- when there are inappropriate behaviours in S1 }\end{array}$ \\
\hline $\begin{array}{l}\text { 2.24 Weak connection between S3 and } \\
\text { S1 (JPR) }\end{array}$ & Operational units work separately without being integrated by S3 \\
\hline $\begin{array}{l}2.25 \text { Weak connection between S2 and } \\
\text { S3 (Authors) }\end{array}$ & $\begin{array}{l}\text { Poor or non-existent exchange of information between } \mathrm{S} 2 \text { and } \mathrm{S} 3 \\
\text { may conduce to the generation of an intrusive or not well informed } \\
\text { S3 }\end{array}$ \\
\hline \multicolumn{2}{|l|}{ System 4} \\
\hline Pathology & Description \\
\hline $\begin{array}{l}\text { 2.26 Weak S4 (RE\&AR) } \\
\text { Headless Chicken (JPR) }\end{array}$ & $\begin{array}{l}\text { Weak stretching archetype - poor S4 } \\
\text { S4 is missing or if it does exist it does not work properly }\end{array}$ \\
\hline
\end{tabular}




\begin{tabular}{|c|c|}
\hline 2.27 Dissociation of S3 and S4 (JPR) & $\begin{array}{l}\text { The homeostat S3-S4 does not work properly. They do not } \\
\text { communicate and interact with each other properly. }\end{array}$ \\
\hline \multicolumn{2}{|l|}{ System 5} \\
\hline Pathology & Description \\
\hline 2.28 Lack of meta-system (JPR) & $\begin{array}{l}\text { Insufficient or non-existent definitions of identity and purpose. A } \\
\text { weak or inexistent meta-system shifts the balance between "there } \\
\text { and then" and the "here and now" management activities towards } \\
\text { the "here and now" leaving adaptation-oriented activities } \\
\text { unattended. Inadequate links exist between the recursion levels }\end{array}$ \\
\hline $\begin{array}{l}2.29 \text { Inadequate representation vis-à- } \\
\text { vis higher levels (JPR) }\end{array}$ & $\begin{array}{l}\text { Poor connection within S5s organizations pertaining to different } \\
\text { recursion levels within the same global organization }\end{array}$ \\
\hline \multicolumn{2}{|l|}{ III. Meta-systemic Interactions } \\
\hline Pathology & Description \\
\hline $\begin{array}{l}\text { 3.1 Poor (or no) differentiation of } \\
\text { primary and secondary activities (JPR) }\end{array}$ & $\begin{array}{l}\text { Operational and management activities (primary and secondary/ } \\
\text { systemic and meta-systemic) are not clearly differentiated }\end{array}$ \\
\hline $\begin{array}{l}3.2 \text { Collapse of S5 into S3 (non-existing } \\
\text { metasystem) (JPR) }\end{array}$ & S5 Intervenes undesirably in the function of S3 \\
\hline $\begin{array}{l}3.3 \text { Poor governance because of over } \\
\text { empowered S1 (Authors) }\end{array}$ & $\begin{array}{l}\text { S1 control most of the resources; their representatives make the } \\
\text { strategic decisions, with not enough involvement from the next } \\
\text { recursive level (e.g. the national government in a regional focused } \\
\text { network) }\end{array}$ \\
\hline $\begin{array}{l}\text { 3.4 Organizational autopoietic beast } \\
\text { (JPR) } \\
\text { Organizational Cancer }(\mathrm{PH})\end{array}$ & $\begin{array}{l}\text { The uncontrolled growth and activity of some individual parts of } \\
\text { the organization put at risk the viability of the whole. } \\
\text { Uncontrollable growth of a group of activities - support activities } \\
\text { growing uncontrollably }\end{array}$ \\
\hline
\end{tabular}

\section{Appendix 3. - Glossary to make a viable system}

Beer (1994) proposes a glossary of rules to make a viable system, which is composed of two regulatory aphorisms, four principles for organization, a theorem and four axioms, which are presented below.

Aphorisms:

\section{First regulatory aphorism}

It is not necessary to enter the black box to understand the nature of the function it performs.

\section{Second regulatory aphorism}

It is not necessary to enter the black box to calculate the variety that can potentially generate. 


\section{Principles:}

\section{The First Principle of Organization}

Managerial, operational and environmental varieties, diffusing through an institutional system, TEND TO EQUATE; they should be designed to do so with minimum damage to people and to cost.

\section{The Second Principle of Organization}

The four directional channels carrying information between the management unit, the operation, and the environment must each have a higher capacity to transmit a given amount of information relevant to variety selection in a given time than the originating subsystem has to generate it in that time.

\section{The Third Principle of Organization}

Wherever the information carried on a channel capable of distinguishing a given variety crosses a boundary, it undergoes transduction; the variety of the transducer must be at least equivalent to the variety of the channel.

\section{The Fourth Principle of Organization}

The operation of the first three principles must be cyclically maintained through time without hiatus or lags.

\section{The recursive system theorem}

In a recursive organizational structure, any viable system contains, and is contained in a viable system.

\section{Axioms}

\section{The First Axiom of Management}

The sum of horizontal variety disposed by all the operational elements EQUALS he sum of vertical variety disposed on the six vertical components of corporate cohesion.

\section{The Second Axiom of Management}

The variety disposed by System Three resulting from the operation of the First Axiom equals the variety disposed by System Four.

\section{The Third Axiom of Management}

The variety disposed by System Five equals the residual variety generated by the operation of the Second Axiom.

\section{The Law of Cohesion (for multiple recursions of the viable system)}

The System One variety accessible to System Three of Recursion x equals the variety disposed by the sum of the metasystems of Recursion y for every recursive pair. 